\title{
QUESTÕES CURRICULARES NA ERA VARGAS (1930-1945): O CASO DA ESCOLA ÉTNICA JAPONESA VISCONDE DE CAIRU
}

\author{
Curriculum aspects in the Vargas Era (1930-1945): The Visconde de Cairu ethnic \\ japanese immigrant school case
}

\section{Custiones curriculares del Periodo Vargas (1930 - 1945): el caso de la escuela étnica japonesa Visconde de Cairu}

Stephanie Amaya*

Jacira Helena do Valle Pereira Assis **

\begin{abstract}
Resumo
Este artigo problematiza questões curriculares da Era Vargas ao analisar as práticas curriculares da escola étnica Japonesa Visconde de Cairu, em Campo Grande, no sul de Mato Grosso. Focaliza o governo Vargas e as políticas educacionais que atingiram as propostas curriculares voltadas aos imigrantes japoneses, por meio da análise de decretos, entrevistas e livros da memorialística. Os resultados sinalizam que os Decretos-lei (1930-1945) promoveram a política nacionalista de Vargas, bem como prescreveram um currículo mínimo obrigatório de controle pedagógico nas escolas de cunho étnico. O nacionalismo impediu o funcionamento de escolas, proibiu o uso de materiais didáticos em língua estrangeira, restringiu a direção da escola a brasileiros natos e, consequentemente, inibiu a atuação dos imigrantes.
\end{abstract}

PALAVRAS-CHAVE: Currículo. Escola de japoneses. Governo Varguista.

\section{Abstract}

This article questions the curricular issues of the Vargas Age when analyzing cross- curricular practices of Visconde de Cairu Japanese ethnic school in Campo Grande, southern of Mato Grosso. It focuses on Vargas government and the educational policies which have reached curriculum plan for Japanese immigrants, through the analysis of decrees, interviews and memorial books. The results shows that the Decree-Laws (1930-1945) endorse Vargas's nationalist policy, along with instructing a base level required curriculum for pedagogical control in ethnic schools. Nationalism hampered the operation of schools, banned the use of teaching kits in foreign languages, held back headmasters who ought to be born Brazilian and therefore inhibited the activities of immigrants.

KEYWORDS: Curriculum. Japanese school. Vargas's government.

\section{Resumen}

Este artículo científico, problematiza cuestiones curriculares del Periodo Vargas al analisar las prácticas curriculares de la escuela étnica japonesa Visconde de Cairu, en Campo Grande en el sur de Mato Grosso. Enfour el Gobierno Vargas y las políticas educacionales que afectaram las propuestas

\footnotetext{
${ }^{*}$ Mestre em Educação pela Universidade Federal de Mato Grosso do Sul (UFMS). Doutoranda em Educação do Programa de Pós Graduação em Educação da UFMS, de Campo Grande - MS. Membro do GEPASE (Grupo de Estudos e Pesquisas em Antropologia e Sociologia da Educação). Professora da Educação Básica em instituição pública de Campo Grande - MS. E-mail: stephanie@ hotmail.com.

** Doutora em Educação pela Universidade de São Paulo (USP). Professora titular da Faculdade de Educação da Universidade Federal de Mato Grosso do Sul (UFMS), em Campo Grande - MS. E-mail: jpereira.dou@terra.com.br.
} 
curriculares direccionadas a los immigrantes japoneses, mediante análisis de decretos, entrevistas personales y libros de la memorialística. Los resultados señalan que los Decretos Ley (1930 - 1945) promovieron la política nacionalista de Vargas, así como prescribieron un currículo mínimo obligatório de control pedagógico em las esculas étnicas. El nacionalismo impedió el funcionamento de las escuelas, prohibió el uso de materiales didácticos em lengua extranjera, restringió la administración de la escuela a los brasileños de nacimiento em consecuencia inhibió la actuacion de los inmigrantes.

PALABRAS CLAVE: Currículum. Escuela japonesa. Gobierno Varguista.

\section{INTRODUÇÃO}

A proposta deste artigo é problematizar questões curriculares organizadas na Era Vargas (1930-1945), com vistas a identificar os rebatimentos da política no currículo de uma escola étnica, particularmente, a Escola Japonesa Visconde de Cairu, em Campo Grande, no sul de Mato Grosso.

O governo de Getúlio Vargas foi marcado por pensamentos e ideais nacionalistas, por vezes ditatoriais, que afetaram os imigrantes no Brasil. Diante desse fato histórico, partimos da seguinte problematização: quais as discussões curriculares, as quais se materializaram em parte da política educacional na/da Era Vargas, que influenciaram a escola étnica japonesa Visconde de Cairu em Campo Grande, no sul de Mato Grosso?

Para melhor compreensão, utilizamos, nas análises das fontes documentais, o aporte teórico do sociólogo Pierre Bourdieu e seus interlocutores no que tange aos conceitos de campo e estratégia.

O artigo está organizado em duas partes. Na primeira trazemos uma breve revisão dos acontecimentos no campo educacional brasileiro na Era Vargas. Na segunda, discutimos as propostas e práticas curriculares das escolas étnicas em geral e, especificamente, da escola Visconde de Cairu.

\section{Campo educacional brasileiro na Era Vargas (1930-1945)}

O cenário educacional brasileiro na Era Vargas compreendeu um momento de conflitos e mudanças políticas, sociais, econômicas e históricas. Nesse sentido, damos ênfase a alguns dos fatores mais importantes para a educação no período de 1930 a 1945, ou seja, do primeiro governo de Getúlio Vargas.

A escola, na conformação do Estado nacional, tinha o objetivo de construir o sentimento de identidade nacional por meio de comportamentos, hábitos e valores condicionados pela disciplina, pelo trabalho e pela contenção corporal (MULLER, 1999). "Nesse sentido, costumeiramente o nacionalismo defende a diversidade cultural, mas impõe a homogeneidade [...]." (PEREIRA, 2000, p. 87).

Do mesmo modo, são encontradas contradições nos discursos e práticas:

A Escola pública é, portanto, a instituição da nação, no dúplice sentido que a expressão pode comportar: sua principal tarefa é instituir a nação como uma realidade mas, ao mesmo tempo, é ao fundamento nacional que ela deve sua criação. [...]. (VALLE, 1997, p. 22). 
De fato, [...] "o Estado nacional sempre objetiva criar uma cultura, permeada por símbolos e valores comuns, diferentemente da nação, que compartilha cultura, valores e símbolos". (PEREIRA, 2000, p. 82), ou seja, uma educação prevista como projeto nacional.

Nesse sentido, torna-se relevante para a compreensão desse processo o conceito de estratégias. Segundo Bourdieu (2011), as estratégias são ações que podem ser conscientes ou inconscientes, que estão atreladas ao campo como um conjunto de relações em determinado local. Cada espaço pode constituir um campo: cultural, econômico, educacional. Dentro do campo educacional proposto para o estudo, identificamos o interesse governista em estabelecer o estado nacional.

Para a implantação do ideário de construir a nação com o apoio do aparelho escolar foram promulgados Decretos-leis, no contexto brasileiro. Dentre eles destacaremos as seguintes: o Decreto-lei n. 18.890, de 18 de abril de 1931, que teve ajustes com o Decreto n. 21.241, de 4 de abril de 1932, fez parte da Reforma Francisco Campos e o Decreto-lei n. 4.244 de 09 de abril de 1942 (Reforma Capanema). Como exemplo, citamos logo abaixo dois artigos do Decreto, que consolidou a estruturação do ensino secundário, componente da Reforma Educacional Francisco Campos:

Art. $2^{\circ} \mathrm{O}$ ensino secundário compreenderá dois cursos seriados: fundamental e complementar.

Art. $3^{\circ}$ Constituirão o curso fundamental as disciplinas abaixo indicadas, distribuidas em cinco anos, de acordo com a seguinte seriação: $1^{\text {a }}$ série: Português - Francês História da Civilização - Geografia - Matemática - Ciências físicas e naturais Desenho - Música (canto orfeônico). $2^{\mathrm{a}}$ série: Português - Francês - Inglês - História da Civilização - Geografia - Matemática - Ciências físicas e naturais - Desenho Música (canto orfeônico). $3^{\mathrm{a}}$ série: Português - Francês - Inglês - História da Civilização - Geografia - Matemática - Física - Química - História Natural Desenho - Música (canto orfeônico). $4^{\mathrm{a}}$ série: Português - Francês - Inglês - Latim Alemão (facultativo) - História da Civilização - Geografia - Matemática - Física Química - Historia Natural - Desenho. $5^{\text {a }}$ série: Português - Latim - Alemão (facultativo) - História da Civilização - Geografia - Matemática - Física - Química Historia Natural - Desenho.

Parágrafo único. Alem das disciplinas constantes da seriação instituida neste artigo, os estabelecimentos de ensino secundário poderão ministrar o ensino facultativo de outras, uma vez que não seja alterado o regime de horas semanais referido no art. 34 . (BRASIL, 1932, p. 1).

Observarmos no Decreto a presença de um currículo enciclopédico, em que a duração dos ciclos e principalmente as avaliações e condições impostas demonstram a seletividade imposta, uma vez que, a “[...] grosso modo, era dirigido às elites e partes das classes médias. [...]”. (DALLABRIDA, 2009, p. 186). O conjunto proposto pelas normas expõe o caráter elitista e conservador da educação nessa época.

Dessa forma, procura-se refletir sobre a cultura escolar do ensino secundário brasileiro definida na Reforma Francisco Campos. Ou seja, intenta-se compreender a escolha e a disposição dos saberes e das habilidades fixadas pelos decretos elaborados pelo Ministério da Educação e Saúde Pública e oficializados pelo Governo Provisório. Numa perspectiva histórica, considera-se que se trata de um conjunto de normas que procuraram modernizar o ensino secundário brasileiro. (DALLABRIDA, 2009, p. 186). 
O sentido de modernizar confunde-se com a inovação da educação e dos modos de ensino a partir de modelos advindos de outros países. Para Dallabrida (2009), seria a perspectiva escolanovista que estimulou a utilização de métodos ativos e individualizantes no processo de aprendizagem.

Para Dewey (2002, p. 18), um dos expoentes desse movimento, “[...] as modificações em curso nos métodos e programas educativos são em igual medida um produto das mudanças na situação social e um esforço para satisfazer as necessidades da nova sociedade." Embora esse momento educativo defendesse que partia de um ponto de vista amplo e social, compreendendo o desenvolvimento de cada indivíduo, representava, por outro lado, uma parcela pequena da população.

Destarte,

\begin{abstract}
Os objetivos e as intenções da escolarização são expressos no currículo escolar, que é resultado de um processo histórico de conflitos de interesses e concepções político-sociais e, como tal, está sujeito à mudanças e evoluções; inclusões e abandono de conceitos, conteúdos e práticas. Ele é documento e testemunho da escolarização institucionalizada de determinada época e sociedade. (ROCHA, 2013, p. 235).
\end{abstract}

Parte desse processo dá-se pelo estabelecimento de um currículo oficial, que indica o que dever ser apreendido e ensinado. A escolha destes conteúdos necessariamente exclui conhecimentos e culturas em favor de outros, ou seja, é arbitrária em relação à seleção e imposição do que é legítimo. (GONÇALVES; GONÇALVES, 2010).

A escola, historicamente, apresenta-se como um campo que tem um papel primordial e faz parte desse espaço de lutas. Segundo Bourdieu (2004) o conceito de campo designa um é dotado de leis próprias no qual se encontram as disputas sociais, políticas e econômicas, que, nessa perspectiva, também estão presentes no campo escolar.

Enfatizamos, assim,

[...] que a relação entre contexto sócio-econômico-político, educação e currículo oficial, evidencia-se em todos os períodos, à medida que as políticas educacionais e os currículos oficiais são fruto das relações mais amplas que ocorrem na sociedade. Os currículos oficiais, de acordo com os períodos analisados, foram adequados aos contextos, especialmente no sentido de garantia de interesses dominantes, atendendo as necessidades econômicas e políticas, na medida do desenvolvimento da sociedade. (ZOTTI, 2002, p. 79).

Com a Constituição de 1937, imposta pelo governo Vargas com o fechamento do Congresso, há uma deliberação de intervenções curriculares de forma que tornava obrigatórias disciplinas como educação física, ensino cívico e trabalhos manuais. (BRASIL, 1937).

Para Goodson (1997, p. 20): “[...] o currículo escrito é o testemunho público e visível das racionalidades escolhidas e da retórica legitimizadora das práticas escolares." Assim, o Governo Vargas buscou impor, por meio currículo de Educação Física, a exaltação da importância do treinamento físico e postural, bem como ressaltar, por meio da inclusão da disciplina de ensino cívico, a formação do Nacionalismo. 
Na perspectiva de Silva (2014), a Unidade Nacional está ancorada nos conceitos de nação, estado, pátria e povo. Dessa maneira, a escolha das disciplinas está diretamente ligada a interesses políticos do momento histórico.

Podemos apontar com essas breves apresentações um conjunto de normativas voltadas à criação de uma educação que atuasse diretamente na promoção da Unidade Nacional governista de Getúlio Vargas. A educação, ou as práticas curriculares, era assumida como um meio para se transitar entre as relações políticas e a população, configurando-se, assim, como uma estratégia, entendida aqui como:

[...] instrumento de uma ruptura com o ponto de vista objetivista e com a ação sem agente que o estruturalismo supõe (recorrendo, por exemplo, à noção de inconsciente). Mas pode-se recusar a ver a estratégia como o produto de um programa consciente e racional. Ela é produto do senso prático como sentido do jogo, de um jogo social particular, historicamente definido [...] (BOURDIEU, 2004, p. 81).

Consequentemente, dos anos 1930 a 1945, houve conflitos entre as proposições das reformas da educação que buscavam selecionar os conteúdos, tornando-a conservadora, elitista e excludente e a corrente pedagógica escolanovista, que defendia uma autonomia e métodos ativos que não contemplavam toda a população. Ou seja, contradições entre o Manifesto dos intelectuais, que reivindicavam um sistema nacional de educação voltado para todos, o que se tornava um projeto utópico, e as Constituições que apoiavam o governo vigente com disciplinas para "disciplinar" os pensamentos.

\section{Escolas étnicas e suas práticas curriculares: em discussão a unidade nacional}

Ainda que o Brasil tenha recebido muitos imigrantes e se caracterizado pela diversidade étnica, o governo brasileiro não possuía instituições ou um planejamento para famílias de estrangeiros. Em vista disso, nesse tópico descrevemos algumas das movimentações dos imigrantes em território nacional e discutiremos as interferências nacionalistas nas escolas étnicas.

A criação de escolas étnicas no país foi motivada pela escassez de instituições e pela tentativa dos imigrantes de manterem as ligações com o país de origem. Dessa maneira, diversos grupos instalaram escolas étnicas tanto para os estudos na língua de origem quanto para manterem a sua cultura.

Na região Sul do país, a abertura das instituições esteve em grande parte relacionada com a religião praticada. Em outras localidades, as escolas de imigrantes surgiram devido às associações, cooperativas e também pelas igrejas.

Para Kreutz (2000, p. 164), as ações comunitárias dos imigrantes eram importantes na criação escolas que funcionavam como elos, "[...] Tanto assim que esta foi a primeira iniciativa comunitária para várias etnias." A escola possui papel importante para a identidade nacional. Em relação às escolas de imigrantes:

As estruturas de apoio para a escola tinham diferenças bastante marcantes entre as etnias, o que certamente se deve a uma conjunção de fatores, como, por exemplo, tradição escolar anterior, instâncias de coordenação, localização em área rural ou urbana, número de imigrantes e outros. (KREUTZ, 2000, p. 169). 
Kreutz (2000) realizou pesquisas sobre os imigrantes no Brasil e em seu texto "Escolas comunitárias de imigrantes no Brasil: instâncias de coordenação e estruturas de apoio", relatou as experiências das escolas para imigrantes italianos, japoneses, poloneses e alemães.

Sobre os italianos o autor narra que as escolas comunitárias estavam concentradas em áreas rurais com liderança religiosa, assim como os poloneses e alemães. A comunidade japonesa, ao contrário, não foi coordenada pela Igreja (KREUTZ, 2000).

Para demonstrar essa força nacionalista do Governo Vargas, o presidente assinou o Decreto-lei n. 1.006, de 30 de dezembro de 1938, que estabeleceu as condições de produção, importação e utilização do livro didático, com a proibição, no artigo 22 , do uso de livros didáticos em outras línguas: "Não se concederá autorização, para uso no ensino primário, de livros didáticos que não estejam escritos na língua nacional." (BRASIL, 1938, n.p.).

Essa proibição acarretou a produção de livros bilíngues em algumas localidades, a qual era fiscalizada. Com a promulgação do Decreto-lei n. 3.580, de 3 de setembro, de 1941, que dispõe sobre a Comissão Nacional do Livro Didático e dá outras providências, essa proibição se manteve: "Art. $4^{\circ}$ Fica proibida a importação de livros didáticos, escritos total, ou parcialmente em língua estrangeira, se destinados ao uso de alunos do ensino primário, bem como a sua produção no território nacional." (BRASIL, 1941, n.p.).

Isso expõe o período do Governo Vargas, conhecido como Estado Novo (1937-1945), como um momento histórico marcado por abusos e restrições a determinadas ações da vida cotidiana, uma vez que a educação nesse período, a partir de uma visão nacionalista conservadora, apresentou um projeto "[...] fundamentalmente, filantrópico; no interior desta concepção, a educação pública é uma obra eminentemente assistencialista mas, em nenhuma circunstância, institui um Escola Universalizada [...]." (VALLE, 1997, p. 76).

Nesse sentido, as escolas étnicas de imigrantes foram vistas como ambientes contrários ao projeto nacional. No caso dos alemães:

A consequência imediata do "estado de guerra" com a Alemanha foi a proibição das publicações em língua alemã e o fechamento das escolas alemãs. As sociedades recreativas e assistenciais voluntariamente trocaram seus nomes me alemão por outros em português, mas, apesar disso, sofreram algumas agressões. (FIORI, 2003, p. 54).

Essa intervenção foi principalmente após o Decreto-lei n. 406, de 4 de maio de 1938, sobre a entrada de estrangeiros:

Art. 42. Nenhum núcleo, centro ou colônia, ou estabelecimento de comércio ou indústria ou associação neles existentes, poderá ter denominação em idioma estrangeiro. Art. 85. Em todas as escolas rurais do país, o ensino de qualquer matéria será ministrada em português, sem prejuízo do eventual emprego do método direto no ensino das línguas vivas. $\S 1^{\circ}$ As escolas a que se refere este artigo serão sempre regidas por brasileiros natos. $\S 2^{\circ}$ Nelas não se ensinará idioma estrangeiro a menores de quatorze (14) anos. $\S 3^{\circ}$ Os livros destinados ao ensino primário serão exclusivamente escritos em línguas portuguesa. $\S 4^{\circ}$ Nos programas do curso primário e secundário é obrigatório o ensino da história e da geografia do Brasil. § $5^{\circ}$ Nas escolas para estrangeiros adultos serão ensinadas noções sobre as instituições políticas do país. Art. 86. Nas zonas rurais do país não será permitida a publicação de livros, revistas ou jornais em línguas estrangeira, sem permissão do Conselho de Imigração e Colonização. Art. 87. A publicação de quaisquer livros, folhetos, revistas, jornais e boletins em língua estrangeira fica sujeita à autorização e registro prévio no Ministério da Justiça. (BRASIL, 1938, n.p.). 
Isto posto, as escolas de imigrantes tornaram-se alvos de depredações e de xenofobismo mais acirrados com os países do Eixo (Alemanha, Itália e Japão) durante a Segunda Guerra Mundial. É importante ressaltar que esses imigrantes possuíam um forte nacionalismo e a intenção de retornarem para sua pátria.

\begin{abstract}
Assim sendo, a escola "estrangeira" não era fruto de um desejo nacional de pluralidade cultural, mas fora surgindo um pouco ao acaso do jogo de forças sociais, para cobrir os espaços de omissão do governo no sentido de propiciar escolas públicas aos grupos imigrantes demandados no Brasil. (FIORI, 2003, p. 5).
\end{abstract}

Como podemos constatar, alguns Decretos-lei impediram o funcionamento de escolas, proibiram o uso de materiais didáticos em língua estrangeira, exigiram que os diretores deveriam ser brasileiros natos e que só se poderia comunicar no ambiente escolar utilizando a língua portuguesa. As proibições intencionavam inibir os imigrantes e, principalmente, reforçar a construção do nacionalismo proposto por Vargas.

De acordo com Viñao (2008, p. 180), as disciplinas escolares devem ser entendidas "[...] como algo não dado, senão construído, como um produto social e histórico." Assim, nesse período histórico, as disciplinas que eram ministradas na língua materna dos imigrantes foram banidas do contexto escolar e, por outro lado, as disciplinas como história e geografia do Brasil tornaram-se obrigatórias.

No entanto, é preciso ressaltar, em relação ao currículo, "[...] que o currículo prescritivo não se refere somente ao currículo que foi escrito como documento oficial, resultante das políticas e das negociações sobre o que deve ser ensinado [...]." (MARTINS, 2007, p. 42), ou seja, o currículo inclui, historicamente, a participação da cultura e da sociedade. Nesse sentido, no próximo tópico tratamos especificamente da constituição do currículo na escola étnica de japoneses Visconde de Cairu e de como foram percebidas essas interações sociais.

\title{
Questões do currículo sobre a escola étnica de japoneses - Visconde de Cairu em Campo Grande sul de Mato Grosso
}

Neste tópico, inicialmente trazemos um pouco da imigração japonesa no sul de Mato Grosso a fim de compreender os vínculos políticos, históricos, sociais e educacionais do período Vargas. Em seguida, analisamos as questões do currículo da escola étnica Japonesa Visconde de Cairu, no sul de Mato Grosso.

Os imigrantes japoneses foram atraídos para o estado de Mato Grosso devido à construção da Estrada de Ferro Noroeste do Brasil. O fator comum das imigrações no país era a fundação de associações e colônias nos locais onde se estabeleciam.

Todas essas colônias foram fundadas por grupos de ex-funcionários da ferrovia. A colônia Chacrinha se destacou na história não só por ter sido a primeira, mas porque na localidade foi criada a primeira escola étnica de japoneses, em 1918. Segundo a AECNB (2005), a Chacrinha foi uma colônia que enfrentou constantes dificuldades econômicas no decorrer de sua existência. (NISHIMOTO, 2011, p. 48).

O trabalho de Imagava e Pereira (2006) relata que a fundação da associação em Dourados, no sul de Mato Grosso, estava ligada à escola étnica, pois os imigrantes queriam que seus filhos apreendessem a língua e os costumes tendo em vista o retorno para o Japão.

As escolas étnicas dos imigrantes foram vistas como ambientes de desintegração em que as práticas pedagógicas afrontavam esse novo projeto educativo, razão pela qual 
precisavam ser convertidas em locais de aprendizado, gestação e irradiação de uma exaltação patriótica que tinha o Brasil e seus aspectos culturais como centro. (SANTOS, 2010, p. 86).

Em 1918, foi construída a primeira escola de língua japonesa de Campo Grande. De acordo com o a Associação Esportiva e Cultural Nipo Brasileira (2008), no livro intitulado "Ayumi", a instituição teve de alterar seu nome devido a perseguições do Governa Vargas: "[...] "Hanja", passando para "Escola de Japoneses de Campo Grande", segundo registro em 1925. Em 1927, por orientação das autoridades, foi rebatizada de Visconde de Cairu, [...]." (AECNB, 2008, p. 41).

Na primeira fase da Escola de Língua Japonesa, nome adotado originalmente, o ensino era todo ministrado em japonês, com professores japoneses. A escola cumpria o papel de suprir e reduzir as necessidades da colônia, uma vez que se tratava de uma instituição criada por japoneses e para japoneses e com o espírito de retornar ao Japão. (BRITO, 2000, p. 77).

A última alteração do nome precedeu as normativas de obrigatoriedade, ainda assim foi devido a orientações governamentais. O Decreto-Lei $\mathrm{n}^{\mathrm{o}}$ 406, de 4 de Maio de 1938 somente normatizou sobre a entrada de estrangeiros e, com o art. 42, proibiu a denominação estrangeira. Em relação à escola:

[...] havia também um certo estigma em relação às escolas brasileiras, pois os japoneses achavam estas instituições muito "fracas", sem nível de equivalência com as escol as no Japão, uma vez que este país havia passado por uma série de transformações [...]. (BRITO, 2000, p. 75).

O Decreto supramencionado tem relação com a trajetória biográfica do Professor Luiz Alexandre de Oliveira, figura de proeminência para a comunidade japonesa, principalmente para a escola de japoneses, uma vez que, devido ao Art. 85, havia a necessidade de uma pessoa de nacionalidade brasileira na direção da escola:

Em todas as escolas rurais do país, o ensino de qualquer matéria será ministrada em português, sem prejuízo do eventual emprego do método direto no ensino das línguas vivas. $[\ldots] \S 1^{\circ}$ As escolas a que se refere este artigo serão sempre regidas por brasileiros natos. (BRASIL, 1938).

Brito (2000) menciona o clima de tensão que se instaurou nesse período em função de a colônia japonesa passar a correr o risco de ter seus bens confiscados e a escola fechada caso o professor Luiz Alexandre não assumisse a diretoria, o prédio e até bens de outros imigrantes japoneses.

Para os fins de nossa análise, vale a pena destacar que o Decreto, além de não permitir o ensino de língua diferente do português, estabelecia que as aulas deveriam ser ministradas por professores brasileiros: que as publicações deveriam passar pela censura de um órgão competente, bem como a restrição de manifestações tradicionais. Aqui compreende-se a presença legalmente imposta de professores brasileiros na "Escola de Japoneses" (BRITO, 2000, p. 95).

Essa ameaça e o medo da colônia japonesa demonstravam o que para Bourdieu (2009) é denominado como violência simbólica, funcionando como uma dominação, um mecanismo de significados e significações que legitima o governo vigente na época.

No que se refere ao relacionamento do professor Luiz Alexandre com a escola de japoneses, ele começou a trabalhar na instituição em 1924 e "[...] Foi figura decisiva para evitar o fechamento da Escola Visconde de Cairu e mais tarde o confisco de bens da colônia durante a Segunda Guerra Mundial.” (MINA SAN, 2008, p. 40). 
Para atender à obrigatoriedade, o professor lecionou História e Geografia do Brasil, português e matemática, uma vez que:

O espírito nacionalista presente na conjuntura do país influenciou a organização curricular através das disciplinas de geografia e história do Brasil, no sentido de garantir um conhecimento aprofundado da realidade do país. Estes conhecimentos, num contexto de orientação nacionalista, eram essenciais à educação da elite dirigente. [...] (ZOTTI, 2002, p. 72).

Por conseguinte, para atender ao Decreto-lei n. 1.545, de 25 de agosto de 1939, que dispunha sobre a adaptação ao meio nacional dos brasileiros descendentes de estrangeiros, prescrevendo, em seu artigo 11 que "Nenhuma escola poderá ser dirigida por estrangeiros [...]", houve a necessidade de um brasileiro assumir o cargo de diretor da Escola de Japoneses, e o professor Luiz Alexandre adquiriu o cargo em decorrência disso:

[...] Pelo vinculo que manteve com a escola, como professor e depois diretor, Luís Alexandre foi vezes convocado para prestar esclarecimentos às autoridades, pois havia severa algumas fiscalização das atividades em escolas estrangeiras. Ele gostava de contar sobre um inquérito dos militares sobre os ensinamentos ministrados na Visconde de Cairu. Luís Alexandre lançou um desafio no sentido de que as autoridades fizessem uma visita de surpreender. (MAIS SABER, 1998, p. $33)$.

A escola de japoneses, na visão de Brito (2000, p. 110), "[...] foi uma escola criada para um grupo de pessoas que não tinha domínio do idioma do país acolhedor, [...] expressava a importância dada à educação pelo grupo. [...].” (BRITO, 2000, p. 110).

Isso evidenciava, nos japoneses, um profundo sentimento de nacionalismo, entendido como o "[...] sentimento de pertencer a uma comunidade cujos membros identificam-se com um conjunto de símbolos, crenças e estilos de vida e têm a vontade de decidir sobre seu destino político." (PEREIRA, 2000, p. 89).

Justamente esse sentimento foi o que governo tentou banir com seus decretos, proibições e obrigações, uma vez que "As escolas não apenas controlam as pessoas; elas também ajudam a controlar o significado [...]." (APPLE, 2006, p. 103). Os japoneses, com a criação de suas próprias escolas, tentavam preservar o nacionalismo japonês, enquanto o governo, por meio das restrições impostas, atuava visando a construção de uma unidade nacional brasileira.

Kreutz (2010) acredita que essa tendência de afirmação da unidade estabelece um poder hierarquizado. Nesse período, o Estado brasileiro testava a legislação em vigor por meio de "[...] currículos mínimos obrigatórios, conteúdos nacionais ou 'nacionalistas' transmitidos nas escolas, livros didáticos e outros, criando um sistema federal de regulação e controle das instituições [...]." (PESSANHA; SILVA, 2013, p. 1022).

Assim podemos inferir que as discussões curriculares estavam voltadas à política nacionalista de Getúlio Vargas com Decretos-Lei por meio de imposições aos imigrantes.

Embora o conteúdo das disciplinas da "Escola de Japoneses" fosse semelhante ao das outras escolas existentes em Campo Grande, uma vez que todos eram obrigadas a cumprir algumas exigências comuns impostas pelos órgãos responsáveis pela Educação no país, administrativamente apresentava diferenças. [...]. (BRITO, 2000, p. 79). 
Desse modo, a escola dos imigrantes sofreu alterações no nome da instituição para se manter, bem como teve de contratar professores brasileiros, ficou proibida de ensinar a língua japonesa ou utilizar materiais didáticos/cartilhas/livros importados.

Como exemplo do embate de interesses travado nesse período, Brito (2000) aponta:

[...] A presença de professores brasileiros era legalmente imposta. Segundo alguns depoimentos, além do governo estadual, a escola pôde contar, por um longo período, com o apoio do governo japonês. $\mathrm{O}$ imperador encaminhava o material didático necessário como mapas, esqueletos, montava laboratórios. Para obter tal colaboração bastava escrever solicitando. [...]. (BRITO, 2000, p. 79).

A ajuda material do governo japonês pode ter representado uma afronta política naquele momento. Pois, podemos observar que "[...] as orientações curriculares eram coerentes com o conceito sócio-econômico-político [...]." (ZOTTI, 2002, p. 77). Assim como, a ideologia era imposta com disciplinas específicas e diversos outros mecanismo na educação para a manutenção da política nacionalista.

Ainda que proibido o ensino da língua japonesa na escola, os imigrantes continuaram a ensinar o idioma materno para seus filhos, após a Guerra, o que demonstrou a importância que as famílias dispunham para educação. Assim, “[...]. Em 1947, com a liberação, seu ensino voltou a ser permitido na Escola Visconde." (ASSOCIAÇÃO ESPORTIVA E CULTURAL NIPO BRASILEIRA, 2008, p. 52).

Segundo Bourdieu (2011), no que se refere às estratégias,

[...] é somente com referência ao espaço de disputa que as define e que elas visam manter ou redefinir, enquanto tal, quase completamente, que se pode compreender as estratégias individuais ou coletivas, espontâneas ou organizadas, que visam conservar e transformar ou transformar para conservar. (BOURDIEU, 2011, p. 151).

Após a Segunda Guerra Mundial a escola enfrentou conflitos internos por conta da nacionalização, na questão do ensino da língua japonesa. Por fim, procuramos focalizar os fatos importantes para os importantes de japoneses e as discussões curriculares que envolveram a escola étnica Visconde de Cairu.

\section{CONSIDERAÇÕES FINAIS}

A educação na Era Vargas foi vista como um conjunto de práticas curriculares voltadas às propostas políticas nacionalistas, sendo que os decretos e normativas impostos pelo Governo Vargas visavam impulsionar a promoção da Unidade Nacional por meio da educação, amparada na formação da nação, do estado e do povo.

Nesse processo de construção da nação ocidental moderna, a instrução teve um papel fundamental. Os sentimentos de pátria, nação, não existiriam sem a difusão da escola pública, elemento básico para a construção da "identidade nacional". Foi também através da educação que se conseguiu obter a adesão da população aos projetos políticos [...]. (MULLER, 1999, p. 40).

As discussões em torno das Reformas da Educação foram marcadas pelas propostas elitistas e excludentes, pela corrente pedagógica escolanovista, que não contemplava toda a população, pelas discussões de intelectuais no Manifesto dos Pioneiros para a criação de um sistema nacional de educação voltado para todos, um projeto não conquistado até os dias de hoje, e pelas Constituições que apoiavam o governo vigente. 
O nacionalismo esteve presente por meio dos Decretos-lei que impediram o funcionamento de escolas, proibiram o uso de materiais didáticos em língua estrangeira e restringiram a direção das escolas a brasileiros natos. Da mesma maneira, as proibições visavam inibir os imigrantes e, principalmente, reforçar a construção do nacionalismo, em um movimento vertical hierarquicamente desleal, o que nos permite " [...] ver as escolas como parte de um conjunto de relações de outras instituições - políticas, econômicas e culturais basicamente desiguais [...].” (APPLE, 2006, p. 103).

O Estado Brasileiro legislava com um currículo mínimo e obrigatório, mediante ao controle e regulação da instituição japonesa, impostos pelos Decretos-lei. Para Bourdieu (2009, p. 214): “[...] a escola não fornece apenas indicações, mas também define itinerários, ou seja, no sentido primeiro, métodos e programas de pensamento. [...]". Vargas buscou a construção da Unidade Nacional por meio de interferências das propostas educacionais e curriculares.

Em suma, temos por hipótese que a "manobra" realizada pelo professor Luiz Alexandre ao ser diretor e detentor dos bens da escola de japoneses para manter a instituição aberta no período ditatorial do Governo Vargas não foi um movimento isolado.

Ao findar a Guerra, Luiz Alexandre devolveu todos os bens aos representantes da comunidade japonesa (ASSOCIAÇÃO ESPORTIVA E CULTURAL NIPO BRASILEIRA, 2008). No entanto, isso não foi regra para os demais estados, uma vez que Brito (2000, p. 107) relata que "[...] certo médico em São Paulo apropriou-se de um hospital que pertencia aos japoneses, como também aconteceu com escolas em muitos outros lugares."

O que se pode aproximar durante a elaboração desse estudo é a persistência do grupo de imigrantes em manter a língua japonesa sendo ensinada nas residências das colônias e como primeira ação após a Guerra, bem como a ajuda do professor Luiz Alexandre para que se pudesse cumprir as exigências para manter a escola em funcionamento.

\section{REFERENCIAS}

APPLE, M.W. Ideologia e currículo. Trad. Vinícius Figueira. 3 ed. Porto Alegre: Artmed, 2006.

ASSOCIAÇÃO ESPORTIVA E CULTURAL NIPO-BRASILEIRA (AECNB). Ayumi: a saga da colônia japonesa em Campo Grande. Campo Grande, 2008.

BOURDIEU, P. A distinção. 2. ed. Porto Alegre -RS: Zouk, 2011.

BOURDIEU, P. A economia das trocas simbólicas. Trad. Sérgio Miceli. 6. ed. São Paulo: Perspectiva, 2009.

BOURDIEU, P. Coisas ditas. Trad. Cássia R. da Silviera e Denise Moreno Pegorim. São Paulo: Brasiliense, 2004.

BRASIL. Decreto n. 21.241, de 04 de abril de 1932. Consolida as disposições sobre a organização sobre a organização do ensino secundário e dá outras providências. Diário Oficial da União, Rio de Janeiro, 1932. 
BRASIL. Constituição (1937). Constituição dos Estados Unidos do Brasil. Diário Oficial da União, Rio de Janeiro, 10 de novembro de 1937.

BRASIL. Decreto-lei n. 1.006, de 30 de dezembro de 1938. Estabelece as condições de produção, importação e utilização do livro didático. Diário Oficial da União, Rio de Janeiro, 1938.

BRASIL. Decreto-lei n. 3.580, de 3 de setembro de 1941. Dispõe sobre a Comissão Nacional do Livro Didático e dá outras providências. Diário Oficial da União, Rio de Janeiro, 1941.

BRITO, C. R. Escola de japoneses da etnicidade em Mato Grosso do Sul. Campo Grande MS: Uniderp, 2000.

DALLABRIDA, N. A reforma Francisco Campos e a modernização nacionalizada do ensino secundário. Educação, Porto Alegre, v. 32, n. 2, p. 185 - 191, maio/ago. 2009.

DEWEY, J. A escola e a sociedade e a criança e o currículo. Tradução de Paulo Faria; Maria João Alvarez e Isabel Sá. Lisboa: Relógio D’Água, 2002.

FIORI, N. A. (Org.). Etnia e educação: a escola "alemã" do Brasil e estudos congêneres. Florianópolis: Editora Unisul, 2003.

GONÇALVES, N. G.; GONÇALVES, SANDRO A. Pierre Bourdieu: educação para além da reprodução. Petrópolis: Vozes, 2010.

GOODSON, I. F. A construção social do currículo. Trad. Maria Jo

IMAGAVA, C.Y.M.; PEREIRA, J.H.V. O papel das escolas étnica e nacional de educação básica na constituição identitária de gerações de imigrantes japoneses em Dourados - MS. Intermeio (UFMS), v. 12, p. 46-69, 2006.

KREUTZ, L. Escolas comunitárias de imigrantes no Brasil: instâncias de coordenação e estruturas de apoio. Revista Brasileira de Educação, Rio de Janeiro, n. 15, set. /out. 2000.

KREUTZ, L. Escolas étnicas no Brasil e a formação do Estado Nacional: a nacionalização compulsória das escolas dos imigrantes (1937-1945). Poiésis, Tubarão, v. 3, n. 5, p. 71 - 84, jan./jun. 2010.

MAIS SABER. Personalidades: Luiz Alexandre. Revista de Educação de Mato Grosso do Sul, Campo Grande, n. 2, p. 32 -35, 1998.

MARTINS, M. C. Histórias do currículo e currículos narrativos: possibilidades de investigação na história social do conhecimento. Pro-posições, Campinas, v. 18, n. 2, maio/ago. 2007.

MINA SAN. 100 anos da Imigração japonesa. Campo Grande: Correio do Estado, 2008.

MULLER, L. As construtoras da Nação: professoras primárias na Primeira República. Niterói: Intertexto, 1999. 
PEREIRA, A. (Des) contemporaneidade do nacionalismo. In: Helder Baruffi (Org.).

Educação e conhecimento: a formação do educador. Dourados - MS: HBedit, 2000, p. 79-96.

PESSANHA, E. C.; SILVA, F. C. T. História de uma Instituição Escolar: democratização ou elitização do ensino secundário (1939 - 1971)? Perspectiva, Florianópolis, v. 31, n. 3, p. 1021 -1041, set./dez. 2013.

ROCHA, A. A. L. O colégio Maria Constança: a história do currículo e sua materialidade. In: SILVA, F. C. T.; PEREIRA, M. V. M. (Org.). Observatório de cultura escolar: estudos e pesquisas sobre escola, currículo e cultura escolar. Campo Grande - MS: Editora UFMS, 2013.

SANTOS, A. V. Educação e nacionalismo: configurando a escola primária catarinense na Era Vargas. Revista Brasileira de História da Educação, Campinas-SP, n. 24, p. 83-111, set./dez. 2010 .

SILVA, C. B. Nação, região e a unidade nacional uma leitura baseada em dois livros didáticos de história publicados na Primeira República. Revista Brasileira de Educação, Rio de Janeiro, v. 19, n. 57, p. $349-374,2014$.

VALLE, L. A escola e a nação: as origens do projeto pedagógico brasileiro. São Paulo: Editora Letras \& Letras, 1997.

VIÑAO, A. A história das disciplinas escolares. Trad. Marina Fernandes Braga. Revista de História de Educação, Maringá, n. 18, set./dez. 2008.

ZOTTI, S. Sociedade, educação e currículo no Brasil: dos jesuítas aos anos 80. Quaestio (Revista de Estudos de Educação), ano 4, n. 2, nov., 2002.

Recebido em: 16/05/2019

Aprovado em: 19/07/2019 